\title{
Analytical and clinical evaluation of a new immunoassay for therapeutic drug monitoring of infliximab and adalimumab
}

\author{
Francisca Llinares-Tello ${ }^{1, *}$, José Rosas \\ Gómez de Salazar², José Miguel Senabre Gallego², \\ Gregorio Santos Soler ${ }^{2}$, Carlos Santos Ramírez ${ }^{3}$, \\ Esteban Salas Heredia ${ }^{2}$ and Juan Molina García ${ }^{1}$ \\ ${ }^{1}$ Laboratory Department, Marina Baixa Hospital, \\ Villajoyosa, Alicante, Spain \\ ${ }^{2}$ Rheumatology Department, Marina Baixa Hospital, \\ Villajoyosa, Alicante, Spain \\ ${ }^{3}$ Rheumatology Department, Marina Salud Hospital, Denia, \\ Alicante, Spain
}

In the last decade, biological agents have revolutionised rheumatology. Tumour necrosis factor- $\alpha(\mathrm{TNF} \alpha)$ neutralising antibody constructs as infliximab and adalimumab are widely used as treatment for rheumatoid arthritis, ankylosing spondylitis, psoriatic arthritis and psoriasis. Infliximab is a chimeric (mouse-human) monoclonal antibody against TNF $\alpha$. It has been shown to induce the formation of human antichimeric antibodies. Adalimumab is a fully human antibody against $\mathrm{TNF} \alpha$ and therefore thought to be less immunogenic than chimeric antibodies. However, even fully human antibodies may lead to the production of human antihuman antibodies.

Unfortunately, despite the overall effectiveness of these biological agents, a significant proportion of patients do not respond or lose response over time. An explanation may be that antibodies are formed against these therapeutic agents. Another reason could be the necessity of achieving trough anti-TNF $\alpha$ drug concentrations in a target range $(1,2)$.

In addition, the incidence of anti-drug antibodies could be associated with adverse events. Higher concentrations of anti-infliximab antibodies were associated with a higher risk of infusion reactions (3), and severe arterial and/or venous thromboembolic events have been related with the presence of anti-adalimumab antibodies (4).

Until now, in the absence of direct measurement of drug levels and anti-drug antibodies, decision-making in the case of failure to anti-TNF $\alpha$ treatment was based on clinical outcome alone. Recently, a new enzyme linked immunosorbent assay (ELISA) has been developed to detect soluble drug levels and antibody formation among patients receiving

\footnotetext{
*Corresponding author: Francisca Llinares-Tello c/o Colón $1202^{\circ}$ A, 03570, Villajoyosa, Alicante, Spain

E-mail: paquillinares@eresmas.com

Received January 25, 2012; accepted March 9, 2012;

previously published online March 26, 2012
}

infliximab or adalimumab (Promonitor ${ }^{\circledR}$, Proteomika, Derio, Vizcaya, Spain, distributed by Menarini Diagnostics S.A. ${ }^{\oplus}$, Badalona, Barcelona, Spain).

The aim of this work was to evaluate the analytical performance and the clinical validation of these four assays with the purpose of testing the hypothesis that they are suitable for therapeutic drug monitoring of infliximab and adalimumab in treated patients.

Following the recommendations for the optimisation of immunoassays (5), we performed our evaluation of these assays during a period of 6 months and two different reagent lots were used. Intra- and inter-assay variability were evaluated on three different days with two replicates of the same sample in each assay. The linearity was performed by diluting different proportions of a standard from the upper and lower end of the dynamic range for each analyte to be evaluated.

For the clinical validation study, serum was collected from 69 patients with rheumatic diseases treated with infliximab (Remicade $^{\circledast}$, Schering-Plough) or adalimumab (Humira ${ }^{\circledR}$, Abbott Laboratories). Informed consent of the patients was required. Before each infusion of infliximab or subcutaneous injection of adalimumab, $10 \mathrm{~mL}$ of serum was collected and stored at $-20^{\circ} \mathrm{C}$. All sera were tested under standardised conditions specified by the fabricant. Six dilutions of serum samples and 10 for each standard curve were made. All the analytical development was carried out without knowledge of clinical data.

Briefly, in the anti-TNF $\alpha$ drug assay, recombinant human TNF $\alpha$ was coated overnight at room temperature on the solid phase and recognised by infliximab or adalimumab in each case. The therapeutic monoclonal antibody was detected by an anti-human inmunoglobulin specific antibody conjugated to biotine. Serum concentrations of antibodies against these drugs were measured using a double-antigen ELISA based on their capture by drug-coated microplates and their detection by biotine-coupled anti-TNF $\alpha$ drug.

This ELISA has a detection limit of $2 \mathrm{ng} / \mathrm{mL}$ for infliximab and $0.4 \mathrm{ng} / \mathrm{mL}$ for adalimumab. And the cut-off value for the drug is $0.053 \mathrm{mg} / \mathrm{L}$ for infliximab and $0.002 \mathrm{mg} / \mathrm{L}$ for adalimumab. And for antibodies, the cut-off value is $37 \mathrm{UA} / \mathrm{mL}$ for infliximab and $8 \mathrm{UA} / \mathrm{mL}$ for adalimumab.

Descriptive statistics were provided using median (range) or percentages. Statistical analysis was performed using the Sigma $\operatorname{Plot}^{\circledast}$ program. Differences between independent groups were traced with the use of Student t-test for normally distributed values. p-Values $<0.05$ were considered statistically significant. 
Within-run CVs ranged from $7.2 \%$ to $9.5 \%$. Between-day imprecision ranged from $11.9 \%$ to $13.7 \%$. The regression analyses of the data for the linearity studies showed correlation coefficients from 0.990 to 0.993 .

A total of 23 serum samples from 21 infliximab-treated patients (mean age 54.4 $\pm 14.3,10$ males, 11 females), and 54 serum samples from 48 adalimumab-treated patients (mean age $51.4 \pm 15.8,11$ males, 37 females) were tested in the clinical validation study.

All the patients who developed antibodies against infliximab $(n=3,14.3 \%)$ or adalimumab $(n=5,10.4 \%)$ in our study had trough serum concentration below the limit of detection of each assay. In these patients, median concentration of antidrug antibodies were $1282 \mathrm{UA} / \mathrm{mL}$ (range 558-187,000) for infliximab and $4372 \mathrm{UA} / \mathrm{mL}(132-717,824)$ for adalimumab.

In the others, median trough-free levels of infliximab or adalimumab were 11.2 (3.6-73.2) $\mathrm{mg} / \mathrm{L}$ and $6.6(0.1-21.3)$ $\mathrm{mg} / \mathrm{L}$, respectively. The patients with anti-drug antibodies had significantly lower mean trough serum concentration $(\mathrm{p}<0.05)$.

These results correlate well with the clinical findings: patients' responders have absence of anti-drug antibodies and significantly higher serum concentrations of the drug than non-responders (6).

Two adalimumab treated patients showed undetectable drug concentration without anti-adalimumab antibodies, reflecting therapeutic non-compliance that was confirmed later, by asking the patient.

Therapeutic drug monitoring is the optimal way to achieve effective treatment when drugs with interindividual variability are used, such as anti-TNFo drugs. These drugs work best over a small blood concentration range. Below this range, serum anti-TNF $\alpha$ drug concentrations were probably too low to have a therapeutic effect. And above this range, to prevent adverse reactions, dose reduction or interval extension might be possible without the loss of clinical response. Taking into account the high cost of these drugs, it might be more costeffective to adjust anti-TNF $\alpha$ drug dosages according to serum drug concentrations $(2,7,8)$.

Furthermore, one of the mechanisms of response failure is associated with low trough levels of anti-TNF $\alpha$ biological agents consequence of development of antibodies against these drugs (2). Moreover, patients who had developed antidrug antibodies against their first TNF $\alpha$ inhibitor had a clinical response to their second TNF $\alpha$ inhibitor that did not differ from $\mathrm{TNF} \alpha$-naive patients. This also suggests that patients who do not respond to a $\mathrm{TNF} \alpha$ inhibitor, despite adequate serum drug levels and the absence of anti-drug antibodies, are likely to benefit more from a therapy based on another mechanism of action than from another TNF $\alpha$ inhibitor yet again (9).

We evaluated four assays for the detection of infliximab, adalimumab and specific antibodies to each drug, and analysed the serum samples of patients treated with these drugs to investigate the relationship between serum drug levels and antibody formation. The assays exhibited sensitivity, precision, recovery and reproducibility suitable for the intended purpose of the assays (5).
Although differences in assays and diverse patient populations studied make a direct comparison difficult, our results are similar to those reported of previous studies, which have suggested that antibodies against infliximab or adalimumab are found in $19 \%-51 \%$ or $17 \%-29 \%$ of patients receiving these drugs, respectively $(1,2,8,10)$. As we can expect, of these two monoclonal antibodies, adalimumab appears to be less immunogenic that infliximab. Patients with antibodies had lower serum anti-TNF $\alpha$ drug concentrations than without antibodies showing that the presence of antibodies led to more rapid elimination of the drugs via the formation of druganti-drug immune complexes (9).

It should be taken into account that circulating drug can interfere with the detection of anti-drug antibodies, therefore impairing the sensitivity of the anti-drug antibodies assays. However, the clinical relevance in patient monitoring is questionable since antibodies will be likely detected in the following test, since it is expected that the antibody titre will increase over the drug amount. However, this phenomenon is not clinically relevant for the detection of the drug in the presence of anti-drug antibodies, because when a patient is reported as antibody-positive, this implies that either the drug is complexed to antibodies and cannot be measured, or that there is no drug present. Regardless of this, the drug is completely ineffective.

In conclusion, our studies indicate that these infliximab and adalimumab Promonitor ${ }^{\circledR}$ ELISA performed well in terms of precision, linearity and clinical evaluation. With the disponibility of this new commercial available kit, the best blood level range for each drug must be found to be used as a kind of therapeutic target, to take adequate therapeutical decisions or adjustments, or to design patient-specific treatment programs.

\section{Conflict of interest statement}

Authors' conflict of interest disclosure: The authors stated that there are no conflicts of interest regarding the publication of this article.

Research funding: None declared.

Employment or leadership: None declared.

Honorarium: None declared.

\section{References}

1. Bartelds GM, Wijbrandts CA, Nurmohamed MT, Stapel S, Lems WF, Aarden L, et al. Clinical response to adalimumab: relationship to anti-adalimumab antibodies and serum adalimumab concentrations in rheumatoid arthritis. Ann Rheum Dis 2007;66:921-6.

2. Radstake TR, Svenson M, Eijsbouts AM, van den Hoogen FH, Enevold C, van Riel PL, et al. Formation of antibodies against infliximab and adalimumab strongly correlates with functional drug levels and clinical responses in rheumatoid arthritis. Ann Rheum Dis 2009;68:1739-45.

3. Pascual-Salcedo D, Plasencia C, Ramiro S, Nuño L, Bonilla G, Nagore D, et al. Influence of immunogenicity on the efficacy of long-term treatment with infliximab in rheumatoid arthritis. Rheumatology 2011;50:1445-52.

4. Korswagen LA, Bartelds GM, Krieckaert CL, Turkstra F, Nurmohamed MT, van Schaardenburg D, et al. Venous and arterial 
thromboembolic events in adalimumab-treated patients with antiadalimumab antibodies: a case series and cohort study. Arthritis Rheum 2011;63:877-83.

5. Mire-Sluis AR, Barrett YC, Devanarayan V, Koren E, Liu H, Maia M, et al. Recommendations for the design and optimization of immunoassays used in the detection of host antibodies against biotechnology products. J Immunol Methods 2004;289:1-16.

6. Rosas J, Llinares-Tello F, Senabre JM, Santos-Soler G, SantosRamírez C, Salas E, et al. Evaluation of anti-TNF levels and antiTNF antibodies in rheumatic diseases treated with infliximab and adalimumab. Preliminary results from a local registry. Arthritis Rheum 2011;63(Suppl):S2211.

7. Mulleman D, Chu Miow Lin D, Ducourau E, Emond P, Ternant D, Magdelaine-Beuzelin C, et al. Trough infliximab concentrations predict efficacy and sustained control of disease activity in rheumatoid arthritis. Ther Drug Monit 2010;32: 232-6.

8. Méric JC, Mulleman D, Ducourau E, Lauféron F, Miow Lin DC, Watier $\mathrm{H}$, et al. Therapeutic drug monitoring of infliximab in spondyloarthritis: an observational open-label study. Ther Drug Monit 2011;33:411-6.

9. Bartelds GM, Krieckaert CL, Nurmohamed MT, Schouwenburg PA, Lems WF, Twisk JW, et al. Development of antidrug antibodies against adalimumab and association with disease activity and treatment failure during long-term follow-up. J Am Med Assoc 2011;305:1460-8.

10. Wolbink GJ, Vis M, Lems W, Voskuyl AE, de Groot E, Nurmohamed MT, et al. Development of antiinfliximab antibodies and relationship to clinical response in patients with rheumatoid arthritis. Arthritis Rheum 2006;54:711-5. 